\title{
ADVANTAGES AND DISADVANTAGES OF USING MACHINE TRANSLATION IN TRANSLATION PEDAGOGY FROM THE PERSPECTIVE OF INSTRUCTORS AND LEARNERS
}

Mohamad Djavad Akbari Motlaq ${ }^{1 *}$, Tengku Sepora Tengku Mahadi ${ }^{2}$

${ }^{1 *}$ Ph.D. Candidate, Universiti Sains Malaysia; ${ }^{2}$ Full Professor, Universiti Sains Malaysia.

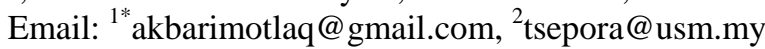

Article History: Received on $10^{\text {th }}$ March 2020, Revised on $24^{\text {th }}$ June 2020, Published on $11^{\text {th }}$ July 2020

\begin{abstract}
Purpose of the study: This paper embodies research on the introduction of machine translation (MT) into translation teaching and learning from the perspectives of learners and instructors/teachers. Four suppositions of employment of MT in translation classes are observed and examined here: MT as a weak (or peripheral) tool, MT as a useful (or essential) tool; MT as a professional treatment; and MT as a CATI tool.
\end{abstract}

Methodology: The objective is achieved using an experimental-survey method with a theory of 'action about reasons' (technology acceptance model) adapted from Davis, Bagozzi, and Warshaw's (1989) work as its framework. The survey tool is done through a closed and open-ended questionnaire while the 'experiment' takes the form of MT introduction practice exercises in the classroom. One hundred Iranian undergraduate students from a translation course with MT in its syllabus and thirty translation instructors make up the population for this study.

Main Findings: In general, students found MT to be useful for producing their translation and seemed, with good exposure through practice, encouraged to use it. The translation educators too saw its benefits but would only be persuaded seriously to utilize it in their translation classrooms when MT is found to produce a much higher quality of output. Otherwise, the disadvantages might outweigh the benefits and thus make the integration of MT into translation teaching not worthwhile.

Applications of this study: Understanding reservations and motivations of translation students and translation instructors from their responses enable translation educators and programmers to redesign their teaching to lessen the challenges and at the same grow their confidence in handling MT and guide them towards efficient and effective use.

Novelty/Originality of this study: To date, the testing of MT in teaching has been done in language education per se. In this study, MT is examined as a tool for better translation teaching, and not as a mode of translation as opposed to human translation. This lends originality to the study.

Keywords: Machine Translation, Pre-editing, Post-editing, Translation Education, Learners' Perception, Teachers' Perception.

\section{INTRODUCTION}

The introduction of the Internet in the last couple of decades as a means of communication has in turn furnished us with a wide range of technological tools or assets for various tasks. While these online tools and assets and other technological tools have been effectively employed by many individual users and organizations for instruction or education purposes, the Internet still stands as a piece of technology and primary device that is and can be utilized for teaching and educating in various subjects. Translation education, for one, can benefit greatly from the internet without having to rely solely on any specific technological tool. General academic tasks, for example, of drawing up a presentation, writing papers, and writing reviews can be accomplished relatively well through the use of the Internet. The user can easily check citations to arrive at valid citations, access relevant articles, share data, or convey messages in several languages. For translation education, these tasks are often embodied in what is referred to as Machine Translation (MT). There are advances in tools that help professional translators to translate volumes of texts and at efficient speeds. For students of translation, however, the Internet can contribute quite well to supplement the role of MT or to make up for the lack of machine tools or the weakness of MT. Following is a brief account of the development of MT that is relevant to the discussion of our title of what entails in the integration of MT into Translation pedagogy.

Vauquois (1968) suggested that MT is planned for empowering a PC to move regular language articulations or form a characteristic language in terms of semantic, syntactic, and lexical measurements. Moving text or discourse from one language into another, while may have obvious and unexpected implications, can be done in a powerful manner using MT. Vauquois (1968) was confident that MT is an appropriate system for translating. Other researchers like Thriveni (2002) seem to have a different opinion of this when he states "one language can't express the significance of another; various languages incline their speakers to think differently....". Thriveni (2002) without a doubt had reservations about translating with the reliance on elements of processors and delicate products of computers. He argued that social understanding and knowledge of characteristic translation (peculiarities of a text for translation) in a translator ought to be taken into consideration for translating to be done well. In other words, writing and culture demands in the contents of texts and discourse cannot be unraveled by a machine. Given the two contrasting views, that is of the strength of MT 
versus the strength of Human Translation (HT), the next step here would be to see how these two can be brought together and what benefit can be gained.

Belam (2002) examined the utilization of MT assessment by senior students in Modern Languages at the University of Exeter. The students were asked to assess the translation output of two MT frameworks, in terms of phrasing and word reference. Belam (2002) found that the students benefited from this task in their overall understanding of the translation process itself and of the workings of a machine. For example, they seemed to have become more aware of professional practice, valuation of composition procedures, estimation of flawed correspondence, and also the expansion of language mindfulness. Usage of MT in classes concerned Niño (2009) who thought of it as a weak tool that could instead harm the learning process. However, some instructors believe that learning a language using MT is more convenient and faster. Here again, we see that there are varying opinions and insight on the usefulness of MT in a language classroom that justifies the present study into translation education. This is particularly timely too with great advances in MT and its supporting tools.

Although there has already been researched related to this issue, the attention was primarily to language and translation mistakes produced through MT and the preparation or knowledge needed to arrest the possibility for such errors. Preparation includes that suggested by Belam (2003) that post-altering can fill in as a supplement (and consequently reduce language teaching costs) because it enables students to concentrate on the source-text contents. Kliffer (2005) investigated a similar issue by examining the utilization of post-altering in a college French-English translation classroom. The students were able to produce a reasonable output using MT. Kliffer claimed that this practice appeared to be increasingly profitable for more fragile students for whom post-altering the outcome appeared to be less unpleasant than doing the entire translation without any other assistance.

The preliminary examination of studies relating to this issue as briefly presented above supports the need for the present paper which sets out to investigate the impression translation students and instructors have on the use of MT tools and free internet-based services in their translation classrooms. It should be stated here that many of the studies were found to be in language learning classrooms. This, therefore, makes the current study and paper on the translation classroom per se more novel. It focuses on MT as a tool to aid translation teaching.

\section{LITERATURE REVIEW}

The work of Niño (2009), Belam (2002 \& 2003), and Kliffer (2005) regarding the application of MT for in language instruction can put forth four primary suppositions.

1. MT used as a weak (or peripheral) tool;

2. MT used as a useful (or essential) tool;

3. Professional treatment: Translation excellence evaluation, pre-altering, and post-altering; and

4. MT used as a "CATI" tool.

Below is a further review of works and foundation studies that demonstrated the above suppositions.

\section{MT used as a weak tool aiding the instruction}

Ball (1989) was among the first few to initiate efforts to study MT within the language category. Ball endorsed the rectification of blunders-discovery in laptop-created translations on the view that the laptop can provide quick evidence of students' ability to use MT in language learning. The output of MT is often viewed as a wellspring of blunders that need to be remedied by language students. Somers (2003:327) supported this point when he said that this utilization will "bring out obscure elements of language contrasts" and "strengthen students' energy regarding each L1 and L2 punctuation and style".

Anderson (1995) and Richmond (1994) in their ways utilized MT as a weak tool. Anderson used a two-way EnglishHebrew MT framework to empower Hebrew-speaking students of English to distinguish and address the MT mistakes on their local knowledge instinct as well as the target language understanding by relying upon translation guidelines. Departing from the source language helps students to become familiar with contrasts between the two languages by highlighting possible translation techniques. A potential weakness of this lies in the need to get students to correct their second language (L2). Richmond (year?) chose to get students to check on their translation by changing or rewriting their L1 to accommodate L1 contents to fit the L2 conventions.

These studies, however, did not directly specify the use of MT in translation teaching and learning, but instead just guided towards the use of MT as a weak tool or a supplementary tool in class. 


\section{MT as a useful tool in instruction}

MT can be perceived as a useful tool in instruction because it includes the application of translation compilations, for example, databases of adjusted or semi-adjusted content sections in various language sets. The use of these databases when blended with that of internet-based word references and lexica, corresponding writings, concordances, and different corpora-based devices may enable students to hone their skills of composition and translation into the L2; and its utilization is particularly suggested with specific languages where testing for suitable wording/diction is principal. Creators, for example, De Cesaris (1995) and Shei (2002a) prescribe the utilization of translation compilations in language courses as a self-guiding asset to test the phraseological and linguistic rightness into L2.

\section{Translation quality assessment, pre-editing, and post-editing in matters of professional development}

The preceding supposition concerning the employment of MT as an essential tool in the teaching and learning of translation is a strong supposition. In like manner, one amongst the first uses of MT in this area is by knowledgeable or experienced translators who, apart from being in command of a minimum of 2 languages, are to be compelled comfortable with the complexities of deciphering meaning and be excited about introducing CAT (Computer-Aided Translation) tools into their work of translating, for example, relying on translation databases or certain MT frameworks. This introduction or integration of MT into translation work needs, however, to be regularly assessed to ensure high, if not excellent, quality in the CAT- human translation output.

Machine translation (abbreviated as MT) outcomes are derived from programmed procedures of moving contents from one human language to another using computer frameworks (Baker \& Saldanha 2012:162). These frameworks utilize particular structures or methodologies, and more often than not yield a crude translation that offers a 'semi-done' translation to the translator to polish in the post-altering stage.

As shown by Liu and Zhang (2015: 116), the crude MT yield represents a noteworthy development in translators' output effectiveness. Moorkens et al. (2015: 267) further highlighted the advantages in terms of the benefit to translation when the MT output quality is adequate and thereby puts less demand on post-altering.

MT frameworks can be classified according to their methodology or design, for instance, model-based (EBMT), free/open-source (FOMT), pragmatics-based (PBMT), rule-based (RBMT), measurable (SMT), crossbreed (RBMT and SMT motors), and Neural (NMT) (Chan 2015: xxix, Koehn 2017). The present investigation will rest on two kinds of the framework: crossbreed and (untouched) SMT.

The SMT framework bases its methodology on ascertaining the chance that an output statement is that of the translation of an offered supply statement, likewise known as the translation form. As stated by Chan (2015: 110): "an RBMT framework uses pointers to coordinate the procedure of MT." The creator learned the arrangements from etymology specialists (detail of standards morphology-targeted, language structure, knowledge then forth.).

In light of this characterization, Systran applies a partial innovation where RBMT segments are created by embracing etymological assets for every language/language pair and utilizing basic or poly-word 'lexical sections' as recreated clarification rules (Dugast et al. 2007). Systran consolidates an SMT module with the uniformity and language constancy of an RBMT module in every phase of the procedure (investigation, move, post-altering) to progress the translation excellence (Systran 2009).

In comparison, Google Translate, the framework selected for this study, is an untouched SMT framework in light of a measurable examination of poly-lingual corpus and utilization of English as a (mediating) language to enable MT with many different languages; this is otherwise referred to as Interlingua (Chan 2015: 111). Instead of depending on rulebased calculations, the framework analyzes the likelihood of a connection between sections of the distinctive language sets dependent on the accessible corpus.

Recently, the two frameworks (Google Translate and Systran) were updated to the NMT method, applying encoderdecoder engineering. Even though there has existed a condescending addition in MT frameworks and the yield or output quality, its useful implementation by the translation businesses currently depends on the idea of post-altering.

Pre-altering includes the change of the source content until a fitting MT yield is acquired. It establishes an imitation type of content control which sounds rather normally utilized in the translation business for the aim of clarification. In language instruction French (1991) bolstered its utilization with generally short messages, urging students to acknowledge what may seem possibly uncertain in the original message to detect the sort of semantic trouble the machine is being confronted. For this reason, the French additionally recommends control of the MT framework's word reference sections by the students. This is yet to be investigated in the field of translation instruction and learning and represents one of the main objectives of the present study.

Similarly, Shei (2002b) arranged for a group of Chinese students of English to compose their theses in English, then to bring them into an MT framework and revise the English original content until the Chinese MT output looks more accurate to them. At that point, the students were solicited to give a rundown from the MT output that they have observed. The main issue about instruction that concerned Shei was that much of the time, the mistakes in the MT output 
were because of deficiencies in the MT framework's sentence structure and word reference and the way to avoid mistakes in the language information available in the system.

Post-altering, on the other hand, involves the preparation of crude or raw MT output into worthy content for a specific reason. La Torre (1999), Niño (2004), Belam (2003), and Kliffer (2005) investigated various employment of postaltering in the course. La Torre (1999) suggested an inventive online asset to more advanced and technology-inclined students of Spanish as a feature of a module on "Prologue to Translation Fundaments" to accustom the students to the latest learning tools available today that seem essential for the post-altering process. The students were assigned specific tasks, for instance, to edit the simple output of a creative text in Spanish into English. Niño (2004) likewise tried to make her language students more familiar with MT by giving them the task of identifying and correcting chunks of errors in MT Spanish translations of general English original texts. This task helped to enhance students' language abilities in both languages and sharpen their translation skills.

In general, the above-mentioned studies informed us of the application of MT as a useful instrument in the teaching and learning of translation. However, there are still gaps in the body of knowledge in MT application in translation teaching and learning; the present study attempts to fill a small gap.

\section{MT in Learning a Language}

Translation has had an awful notoriety in remote/L2 learning and educating. It is regularly connected with the Grammar Translation Method that for a considerable length of time guided the order, and generally included translating source messages from the language being found out (L2) into the primary language (L1). Some think about it as the fifth fullscale aptitude to supplement the other four (talking and tuning in, perusing and composing), which every single instructed bilingual, not simply translators, should ace (Campbell, 2002). Regardless, it is a learning strategy that is proposed for cutting edge students, unquestionably not for tenderfoots (Kaye, 2009). In the next decade, Shei (2002) called attention to the upsides of pre-altering (which "can help understudy learning in the psychological and full of feeling area"), and Kliffer (2005) and Niño (2008) those of post-altering.

These referenced examinations on MT for language learning and the others alluded to by $\underline{\text { Somers (2003) }}$ and Niño (2008), accumulated information utilizing propelled language students or even translation students, never tenderfoots or early middle of the road students. To these groups of examination, we could then include other work with an attention on translation learners or in reality on proficient translators, which has been distributed as of late (Fiederer and O'Brien, 2009; Garcia, 2010; Guerberof, 2009, among others). Two investigations (Cohen and Brooks-Carson, 2001; Kobayashi and Rinnert, 1994) have just watched the impacts of forming a book in L1 and afterward making an interpretation of it into L2.

So as to all the more likely comprehend where financially accessible MT fits into the MT picture in general, it is imperative to understand that there are a few ways to deal with translation that have been utilized or are as yet being utilized. Standard MT scientists by and large perceive three general kinds of framework: direct, move, and interlingua (cf. Goodman and Nirenburg 1991; Nirenburg, et al. 1992; Hutchins 1986; and Slocum 1988). While MT assessment has gotten progressively significant in the previous barely any years, there is by all accounts a general absence of concession to assessment approach (cf. AMTA 1994; NSF 1992; Balkin, et al. 1991; and Neal, et al. 1992). The National Academy of Science's Automatic Language Processing Advisory Committee (ALPAC) (ALPAC 1966), the primary significant MT assessment exertion, was concerned essentially with substance and whether the translated entry is reasonable. ALPAC didn't utilize blunder examination to show up at its assessment results. Other, later approaches (cf. Flanagan 1994; NSF 1992;1 Isahara, et al. 1994; and Neal, et al.1992) don't methodically assess ampleness or education however utilize some type of mistake examination.

\section{Application of MT as a "CATI" tool}

We see presently an increase in moderate MT frameworks, for example, PROMT, French Assistant or Power Translator Pro that consolidate or integrate common and concentrated lexicons as verbal guides towards making it more convenient for users to handle terms or expression components, and syntax; for example, action word conjugators can provide a consistent reference for students.

While we see and acknowledge the potentials of MT and access-free internet-based translation services with the benefit of continuous etymological quality appraisals of MT output, we cannot downplay the idea of MT in translation teaching as a fortunate or an unfortunate model, especially concerning students as users. Students might not be fast enough or motivated enough or adept enough to analyze mistakes in the crude or raw MT to polish or refine it for final consumption worthy of their readers' or clients' satisfaction. Many students might be comfortable just with a quick output or translation on the understanding that the machine is consistent and advance. This argument is one we put forth and would be examining in the present study, that is, to examine and possibly determine the perspectives of translation students and trainers about MT in translation learning. 


\section{Effects of MT and access-free internet-based translation services application}

Some translation students utilize access-free internet-based translation services for translating and translation projects. As per our argument in the section above, the paper cautions by illustrating briefly qualities and possible shortcomings of utilizing MT, and specifically access-free internet-based translation services, from the translation learning perspective.

Access-free internet-based translation services are the most open type of MT, even though it is not the most tested of MT execution and it is for the most part utilized for educational drives as mentioned by Gaspari (2007). It is to get the significance of what an outside content says and less for dissemination purposes where the yield or output reflecting semantic excellence is often mandatory. Sadly, many students do not know or are not able to distinguish between this two primary employment of MT and of the way that access-free internet-based translation services are not especially appropriate for the latter purpose, i.e. for the client's consumption. The fundamental reason is that access-free internetbased translation services comprise a 'discovery' framework that cannot be altered by the language pair, the sort of content to be deciphered, its multifaceted nature, and reason. Indeed, many students, particularly weaker ones or those with moderate or insufficient command of the L2, use the output from access-free internet-based translation services as a tool or language asset for their translation assignments, for the classroom and even for commercial purposes.

According to Niño (2004) in the qualities or perspectives that can urge students to utilize access-free internet-based translation services we can name the following:

- Extensively accessible on the web: Access-free internet-based translation services are broadly accessible as a language asset utilizing web search tools, for example, Google or Bing.

- Imminence: The way that access-free internet-based translation services are prompt; you simply need to choose the original language and L2, reorder the content, or the website page you need to translate and, at a snap, you acquire prompt yield. This establishes an instant electronic item that can be effectively controlled online by the students.

- Poly-linguicism: The way that access-free internet-based translation services are accessible in different language sets and that it enables clients to translate solitary content into a few lingos.

- Decent with verbal translation: The way that access-free internet-based translation services, as a rule, deciphers small verbal components sensibly well. An upper-moderate or highly inclined student can before long decipher and understand that these frameworks free lexical things superior to mixes, phraseological components, or complex linguistic constructions.

- Decent with basically organized texts: The way that access-free internet-based translation services and MT present reasonably well multifaceted organized messages, for example, meteorological forecasts or specialized guides. These sorts of content are typically translated by business MT frameworks with vigorous common and concentrated MT lexicons where wording can be overseen and verbal and linguistic subtleties included request to acquire increasingly precise translations.

According to Gaspari (2007), a portion of the primary shortcomings of access-free internet-based translation services from the translation knowledge perspective are the following:

- Word for word translation: Among the principal shortcomings of access-free internet-based translation services frameworks is the way that there exist typically numerous mistakes in their yield or outputs which are frequently "structure-safeguarding" whether or not in the same words. MT exacting translation includes occasions from the strict translation of legitimate designations, expressions, and connections, relational words, determiners or connectives, to expressions or sentences, the choice of an inappropriate sense or an alternate significance for a specific word, and different word request mistakes.

- Many linguistic errors: One of the issues with access-free internet-based translation services frameworks is that regularly feeble apprentice or middle of the road students rely on them as expression or sentence word references, where punctuation information is required; for example, to exercise what action-word tense, structure or mode is expected to indicate something explicit (a past activity, a desire, an inclination, and so on.) in the target language. The truth of the matter is that students with a more grounded possession of the language do not utilize these frameworks as syntax references since they know about their numerous syntactic mistakes which incorporate different sorts of blunders with relational words, determiners, understanding, pronouns, action word structure, actionword tense, action word style, quantity, and sentence construction.

- Conversational mistakes: Access-free internet-based translation services frameworks and MT frameworks, as a rule, work best when deciphering separate sentences; nonetheless, when translating writings, they yield numerous errors particularly in connection to linking words and co-citation.

- Spelling mistakes: In MT the mentioned mistakes are created when bringing expressions into the framework's lexicons. Even though they are winding up small regular gratitude to the mix of testers of spelling in many business MT frameworks, MT yield may likewise show orthographical mistakes, for example, accentuation and capitalization blunders, letter exclusions, or pointless letters. 
- Unable to represent social references: Access-free internet-based translation services cannot give social reciprocals in the target language except if these are recently distinguished and gone into the framework's word references. Social references include human information and give a test to MT together with other extra phonetic issues, for example, regarding setting, implication, signification, or index.

- "Irregular" composing: An additional impediment is that the frameworks can cultivate an irregular propensity for deciphering.

In the translation class students, particularly those with a low degree of capability can be taught to see what access-free internet services can do or cannot so that students do not rely fully on these online assets for their translation or language composition. Simultaneously students can be shown genuine instances of composing and translation into the target language and be given progressively solid online assets to assess the appropriateness of the output. This may drive the idea that access-free internet-based translation services yield is often of a more regrettable phonetic quality than what they can do. All things considered, students ought to likewise be taught in the conviction that only by getting completely prepared mentally and by the accumulation of innovativeness in their undertakings will they be able to adapt appropriately to expressing themselves in the L2 (Niño, 2004).

\section{MT in translation instruction: practical samples}

Contemplating the above perspectives or scenarios, the present paper will investigate to discover sound illustrations of MT and access-free internet-based translation services application in for translation teaching.

\section{The following are the samples for a useful application:}

The utilization of access-free internet-based translation services output into the students' L1 for abridging purposes at beginners' level or for introducing the task of appreciating a language that cannot be comprehended, to learn about the element of the content.

MT post-altering. Giving the students the original message close to the MT yield and pertinent assets (corresponding writings, word references, punctuation guides, and so forth) for that specific content, and to underscore and address MT yield for a specific reason. Enabling the students to bring terms as well as linguistic data into a business MT framework's word reference.

The utilization of corresponding corpora in or out of MT output. The creator has utilized it in specific translation exercises and it has been demonstrated to be advantageous for mistake distinguishing proof and revision, to instruct how to decipher basic tricky articulations, for style improvement, and diction/phrasing. De Cesaris (1995) indicated that the projects may be adjusted for implementation in a course context as a self-learning asset.

MT assessment. This point/perspective assumes the students have some earlier knowledge of MT, strong language ability, and translation ability. Students may be solicited to assess the MT yield from an MT framework for a specific reason, to analyze the translation nature of various MT frameworks or any other reason to think about various kinds of content that can be deciphered by a similar MT framework.

The last case of decent utilization of access-free internet-based translation services is with firmly connected languages. Translation students, translators, and etymologists keen on learning by correlation firmly connected languages, e.g. Persian and Arabic or Latin and French, can gain proficiency with the likenesses, contrasts, and mannerisms between them. True to form, the yield of access-free internet-based translation services frameworks will, in general, reflect the existence of finer phonetic quality if the original and L2s are firmly connected than when contrasted with languages that vary generously in syntactic, morphological and verbal assembly.

Investigating a poly-lingual framework's syntactic standards and additionally, word references may furnish our abilities with advantaged data in regards to the complexities of the various languages; and, by presenting basic "reenacted" models in the L1, we can perceive how the translation is made and gain from any potential mistakes.

\section{The following are the samples of weak application:}

Implementing an access-free internet-based translation services framework for target language composing or for converting into the target language without owning a decent command of the target language and some past learning about the sort of mistakes an MT framework yields;

Focusing on access-free internet-based translation services yield as an item, not contemplating that it is nothing but an intricate sort of MT framework and without understanding the various phases of investigation, move/interlingua, age, and post-altering (

With non-firmly related languages, for example, Malay and English, in MT and access-free internet-based translation services frameworks, almost certainly the nature of the translation will fail to impress anyone because of remarkably lexical-semantic and basic contrasts bilingually. 
Offering inadequately equipped students access-free internet-based translation services yield with a considerable level of different sorts of mistakes to be remedied, without a reasonable target (for example insignificant post-altering) or regardless of a sign of the forthcoming end client and the fundamental motivation behind the content;

Selecting an incorrect source content or a source content not truly appropriate for MT, for example, a horoscope brimming with informal articulations or a complex scholarly concentrate; and last but not least

Not acquainting MT appropriately with students, for example exhibiting a concise history, its primary points, favorable circumstances, weaknesses, and fundamental contrasts when contrasted with access-free internet-based translation services.

Cultivating consciousness of the probable and confinements of MT is basic for both translation instructors and students and will ideally help to utilize this innovation.

\section{METHODOLOGY}

Davis, Bagozzi, and Warshaw (1989) developed a theory of 'action about reasons' (technology acceptance model) which supported the work of Fishbein and Ajzen (in Davis et al, 1989) to research the reasons people use computers and their attitudes towards them. Their model, shown in Figure one, links the perceived quality and simple use with the perspective towards exploitation of ICT and actual use (system use). They tested this model with 107 adult users, and the World Health Organization had been employing a social control system for fourteen weeks. They found that people's laptop use was foretold by their reasons to be used for which perceived quality was powerfully joined to those reasons. This theory offers the main guide for the present study to justify better the learners' and instructors' perceptions regarding the use of MT in Translation education. According to this model, (as can be seen in figure 1), external variables affect the two main fundamentals labeled as usefulness and ease of use. This influence is drawn from attitudes toward using and will lead to the behavioral intention to use. The actual system used is the output according to this model.

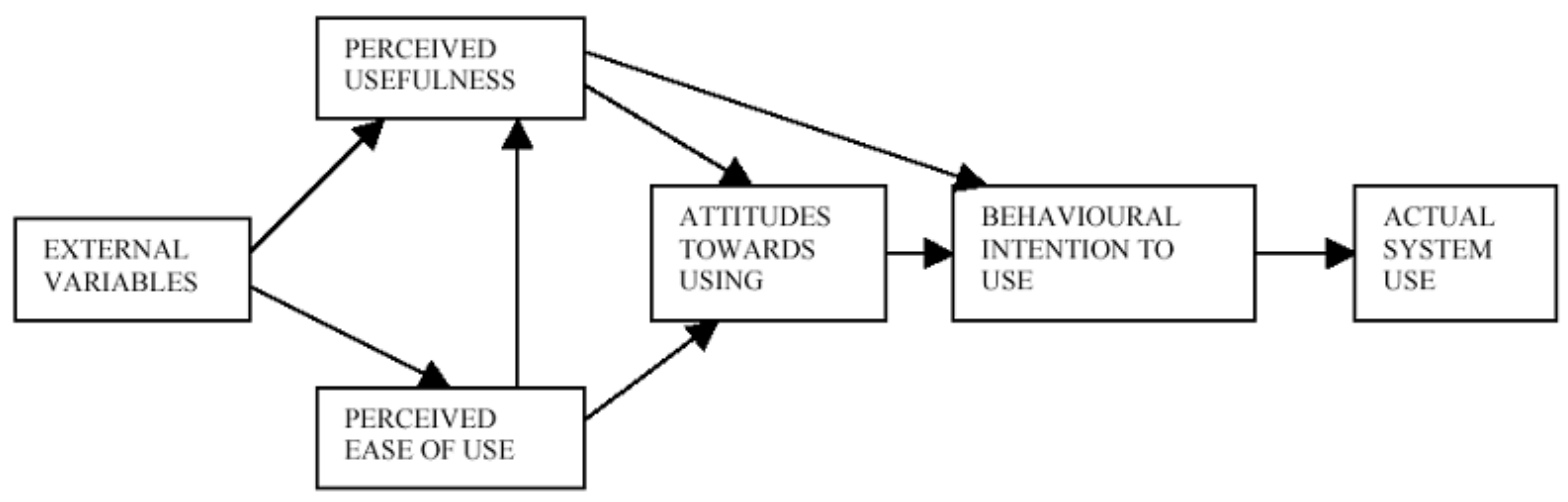

Figure 1: Technology acceptance model (Davis, et al., 1989, p.985)

A hundred translation students from degree level in their final year of study were selected from a translation course where MT is part of the syllabus. Their ages ranged between 22 to 30 and all of them were male participants. Their native language was Persian and they had a good command of English based on their TOEFL test results. Thirty instructors of translation studies at higher level education from Tehran in Iran were chosen for cluster sampling from a hundred members. $40 \%$ of the members were somewhere in the range of 30 and 40 years of age, $30 \%$ were somewhere in the range of 50 and 60 years of age, 20\% were somewhere in the range of 40 and 50 years of age, and 10\% were under 30 years of age. A dominant part of them (55\%) were female. They were native speakers of the following language: Persian, and they were fluent in English.

The main overview (see Appendix A) was routed to a gathering of thirty advanced students of translation who underwent a ten-week basic class in MT and MT post-altering. What follows will be the reaction to six open inquiries, planned for assessing the students' frames of mind towards utilizing crude MT yield as a contribution for translation composed generation; and this is expected to uncover experiences into the strategies opted by students when postaltering the translation. To get familiar with the assessments of translation instructors on the utilization of MT for translation instruction and learning, we did an overview (see Appendix B) to get some answers concerning their frames of mind and perspectives towards translation and MT as academic instruments in the translation class. Both groups of participants were provided with consent forms to assure them that their personal information will remain confidential.

In this study, we used two surveys validated and standardized by Niño (2009). The first survey was to investigate the students' perceptions and the second survey to discover the instructors' perceptions toward using MT in translation courses. The learners' insight survey includes 8 categories in the first section and 6 inquiries in the second section, and the instructors' insight survey includes 28 inquiries. Both surveys ask the questions in a way that the participants can add comments and write their justification in case it is needed. In the students' survey, the first part includes multiple-choice 
questions, however, in the second section the students were able to write their answers and comments. In the instructors' insight survey, the participants were able to add their comments in case it is necessary for any of the items.

For the data analysis, the study used the software SPSS for the quantitative part of the survey results and the paper further supports the results by compiling and the student participants' comments in the surveys.

\section{RESULTS/FINDINGS}

\section{Insight into the application of MT for translation teaching and learning from translation educators and trainers and learners'}

In the above sections, different perspectives and proposals for the application of MT and access-free internet-based translation services in the translation class have been investigated. This section presents the findings from two surveys (overviews) on the view of both translation students and translation instructors about the application of MT for translation instruction and educational aims.

\section{The application of MT for translation learning: learners' insight}

Table 1: The application of MT for translation learning: learners' insight

\begin{tabular}{llll}
\hline Inquiry & Yes & No & Neutral \\
\hline $\begin{array}{l}\text { Have you tried the MT yield previously or in the wake of doing your } \\
\text { post-altering? }\end{array}$ & $81 \%$ & - & $19 \%$ \\
$\begin{array}{l}\text { Have you utilized some other translation tools for your MT post- } \\
\text { altering? }\end{array}$ & $89 \%$ & - & $11 \%$ \\
\hline Are you going to utilize MT later on? & $50 \%$ & $10 \%$ & $40 \%$ \\
\hline Do you think MT is a helpful translation tool? & $82 \%$ & - & $18 \%$ \\
\hline Has MT helped you to improve your level of translation ability? & $70 \%$ & $11 \%$ & $19 \%$ \\
\hline Has MT given you more trust in your translation composed generation? & $65 \%$ & $15 \%$ & $20 \%$ \\
\hline
\end{tabular}

To the inquiry "Which procedure have you followed in your post-altering, for example, have you tried the MT yield previously or in the wake of doing your post-altering?" $81 \%$ of the students revealed having tried the MT yield previously or when their post-altering for reference and checking purposes, and the rest did not give a response.

To the inquiry "Have you utilized some other translation tools for your MT post-altering? Assuming this is the case, which one?" $89 \%$ of the students admitted to having referred to different resources, for example, yields from various online MT frameworks, online lexicons and glossaries, web crawlers, and parallel texts; and the rest did not give a response.

To the inquiry "Are you going to utilize MT later on?" 50\% of the students said that they would utilize MT later on. Among the assets, the students used included the tool of content checking in different languages, as a speedy verbal aiding tool, with specialized contexts, and to acquire a fast draft from which to expand or refine.

To the inquiry "Do you think MT is a helpful translation tool?" $82 \%$ of students thought that MT is a useful language tool. They contended that MT is fast, easy to use, and can give a beginning draft. They additionally expressed that it tends to be exceptionally helpful with jargon, particularly with wording.

To the inquiry "Has MT helped you to improve your level of translation ability?" 70\% of understudies communicated that MT had added to their translation development. The participants clarified that cleaning the crude MT yield had advanced their mistake identification and remedy aptitudes, had urged them to retranslate mistakes, had sharpened their perception abilities and had additionally made them center around translation use and on precision.

To the inquiry "Has MT given you more trust in your translation composed generation?" $65 \%$ of the students communicated that practicing MT post-altering into the translation had helped them to be more confident in translation composed generation. They contended that the practice furnished them with progressive self-assessment methodologies, with better translation preparation, with somewhat more confidence in their translation capabilities, and with the learning of the conceivable outcomes and impediments of MT.

\section{The application of MT for translation instruction: translation instructors' insight}

MT was natural to $70 \%$ of the members. A large percentage of them (55\%) were introduced to the possibilities of online MT. 55\% of the members utilized MT frameworks, $45 \%$ of them likewise had utilized business MT frameworks.

Table 2: Concerning recurrence of utilization

\begin{tabular}{cccc}
\hline & $\begin{array}{c}\text { Utilized MT a few } \\
\text { times }\end{array}$ & Never utilized & Not familiar \\
\hline Recurrence of utilization & $55 \%$ & $20 \%$ & $25 \%$ \\
\hline
\end{tabular}


Table 3: The principal inspiration for utilizing MT

\begin{tabular}{ccccc}
\hline & For interest & Initial step & $\begin{array}{c}\text { Perusing writings } \\
\text { in different } \\
\text { languages }\end{array}$ & Not specified \\
\hline $\begin{array}{c}\text { Principal inspiration } \\
\text { for utilizing MT }\end{array}$ & $30 \%$ & $10 \%$ & $20 \%$ & $40 \%$ \\
\hline
\end{tabular}

Concerning recurrence of utilization, 55\% of the members utilized MT a few times each year and $20 \%$ had never utilized it. Regarding their principal inspiration for utilizing MT, 30\% used MT for interest, $10 \%$ as an initial step, and $20 \%$ for perusing writings in different languages. Different uses indicated were: to instruct students about the semantic constraints of MT yield, to show language obscurities in MT, and for research.

Table 4: Utilization of translation for educational purposes

\begin{tabular}{lccc}
\hline & From L1 into L2 & $\begin{array}{c}\text { In the two language } \\
\text { bearings }\end{array}$ & $\begin{array}{c}\text { A way of } \\
\text { progressing }\end{array}$ \\
\hline $\begin{array}{l}\text { Utilization of translation } \\
\text { for educational purposes }\end{array}$ & $25 \%$ & $22 \%$ & $53 \%$ \\
\hline
\end{tabular}

Concerning utilization of translation for educational purposes, $60 \%$ of the members had used translation as an instruction/learning device, for the most part from L1 into L2 (25\%), and in the two language bearings (22\%), and as a way of progressing or achieving better levels (53\%), and half of the translation educators used it concerning general texts. The fundamental objectives set for the utilization of translation as an academic tool were the following: for enhancing the skill of appreciating texts, sharpening the ability to compose critically in the target language, achieving the know-how to modify as necessary, preparing translation especially to achieve a close equivalent to the source text, and evaluating translations.

As far as MT application in the translation course is concerned, only $23 \%$ of the members had utilized MT in moving both from the source language into the target language and vice versa, in enabling progression in class, and in handling both general and specialized texts. The fundamental objectives set for the utilization of MT in the translation course were the following: for helping students to prepare for composing in the L2, teaching them to modify and evaluate, enhancing appreciation of the target language, and assisting students in their translation preparation. Every one of the members who utilized MT in their exercises thinks it is somehow difficult to utilize. Many of them may want to incorporate practical instruction on MT in their classroom.

Table 5: Utilization of MT in the future

\begin{tabular}{cccc}
\hline & May utilize & May not utilize & Neutral \\
\hline $\begin{array}{c}\text { Utilization of MT in the } \\
\text { future }\end{array}$ & $27 \%$ & $23 \%$ & $50 \%$ \\
\hline
\end{tabular}

Out of the members who have not utilized MT in the exercises $27 \%$ may utilize it, $23 \%$ may not utilize it, and the rest had not given a response. The members who might use MT in the translation class may utilize it for translating various texts, both from the source language into the target language and vice versa, and mainly with online MT frameworks, and using general original writings. The principle objectives indicated for the utilization of MT as an instruction/learning tool in the translation course were the following: for post-altering and pre-altering drives, as a translation practice, to practice comparison examination, for translation training, to increase cognizance of the intricacy of translation, for understanding drives, for correcting, and making students more aware of the fundamental impediments of MT. The final part of the translation instructors' overview comprised three inquiries of an open nature. In the sections below the paper summarize the responses gathered.

Regarding the inquiry "How would you propose that MT be utilized in the translation class?" Members recommended the following: to increase understanding of the common signs of a translation content at the level for amateurs, enable the practice of post-altering in a translation course, sharpen students' ability to identify mistakes and the causes, enable students to see how assessing MT yield can help to improve on the quality of their final translation output, allow students to arrive at initial drafts and understand the process leading to this stage, and compare and contrast the MT yield and the students' yield and arrive at an example target message that can help to demonstrate the possible impediments of MT.

To the inquiry "Which favorable circumstances do you think MT has for translation instruction/learning purposes?", these points were the primary reactions of the members: this involves mistake recognition and preparation; it includes composed creation training; it is easy to understand, and this is quick. Other points of interest communicated by the instructors were: the educator can control the information content; it produces first drafts to mark at; it effectively makes instant translations for instruction; it includes proficient preparing; it encourages contrastive investigation, also, raises cognizance of the unpredictability of translation; it investigates the job of ethos in MT, and it urges students to be mindful of the possible traps of MT. 
Last, regarding the inquiry "Which impediments do you think MT has for translation instruction/learning purposes?", these points were the fundamental reactions of the members: inadequate quality; content sort imperative (not reasonable for innovative translations); it necessitates preparing; therefore, it might be a weak tool (particularly with fledglings and lower intermediate level students). Other comments put forth by the members were that it is to structure centered, that it might cause prompt over-alteration, that it is problematic, that it suggests a great deal of work and does not generally give influential outcomes, and that it does not, for now, give an excellent translation.

\section{DISCUSSION / ANALYSIS}

Further remarks by the students demonstrated that the practice had provided them better language mindfulness, understanding of precision, and higher confidence in translation generation. The students portrayed this action as simply trying to utilize, and non-undermining. Many of them added further that after the experience they had built up a superior disposition towards MT. These findings are following Niño (2009), Gaspari (2007), and Niño (2004).

Concerning the translation acceptance model of Davis et al (1989), external variables may have an impact on the perceived usefulness and perceived ease of use. The perception of the majority of learner's usefulness and ease of use are two items that are of high importance in a course where MT is implemented to help the translation education. The instructors share equally this view; however, they believe that what is currently implemented as MT in the translation course is not yet adequately advanced and cannot help the learners learn much better or the teachers to teach more efficiently and effectively, they also have the opinion that the usage of MT might corrupt their learning by fossilizing wrong translated terms or mislead them in terms of the appropriate strategies to use. It is also the instructors' perception that MT might be much better improved shortly.

Regardless, we accept that students of all levels would concur that the access-free internet-based translation services make it easy for them to search for relevant information and vocabulary for their translation work, though they know that full reliance on online output or sources is not allowed in a translation class.

As more advanced students understand better, on the one hand, the advantages of access-free internet-based translation services (speedy, simple to use, non-compromising), and on the other, the disadvantages (lower accuracy, reliance on language pair and kinds of content), they would feel they are in a better position to decide. Dependable human translations further support this understanding. With this knowledge in their translation planning process, it is most likely less tedious to have a go at composing content or translating a text into the target language oneself, with the aid of the web-references, especially the ones to check for exactness and accuracy of information and words. A native speaker or translator or a language or translation expert should be consulted for more complex issues, for example, mistranslation, the semantic margins (ampleness), language implication, and other cultural, sociolinguistic, and social issues. The findings are following Somers (2003), Belam (2002 \& 2003) and Kliffer (2005).

On the whole, in light of the students' answers, exposure to MT in translation learning was helpful through translation practice exercises that seek to enable students to recognize and amend mistakes in the MT yield. These exercises set in motion of evaluating full documented language (i.e. in the form of texts), its translation, and MT information and the action of being mindful of possible impediments of MT from a professional perspective.

Following the research by Niño (2009) and Somers (2003:327), the translation educators and instructor's responses led us to the discovery that most of them have considered MT in their language teaching, particularly concerning the uses of access-free internet-based translation services. However, only a small number of them attempted to evaluate the nature of its yield to determine the types of mistakes MT is capable of making and the extent to which they can recognize these mistakes in their students' output. Their etymological interest, however, had not kept them from utilizing the frameworks to understand better the viability of producing an initial draft in various languages. Most of the participants had utilized access-free internet-based translation services from the source language into the target language, specifically for translation testing purposes. Only a small number of the trainers and instructors used MT in their translation courses for the translation of both general and specialized translations and from the lower intermediate onwards.

The paper accepts that translation instructors value original writing produced by students based on their translation abilities that are sharpened through practice exercises to amend, compose, and evaluate in the translation classroom. It notes that they are open to the idea of assistance from the machine, especially at certain stages to achieve accuracy. Departing from this, we can suggest that MT is by all accounts a reality that merits researching for purposes of translation teaching. It should be highlighted here that translation instructors with knowledge of or a foundation in MT have compassion for MT from an etymological perspective. Many might be prepared to study how MT can be incorporated into the lesson plans in the translation class, for example, whether it is practical to do so at the stages of pre-altering, post-altering, contrastive examination, and analyzing the quality of the output.

Though there is positive thinking in general, the following are still major concerns of many.

a. The small amount of perfect output can be a limiting factor for MT to be used in class, particularly with lower-level students;

b. Access to original or source texts with the appropriate contents or contents planned for the course may be limited; 
c. The selection of exercises and texts for exercises should be guided by how well documented online the L2 is, the availability of online sources or tools for reference, and other relevant MT information; and

d. The daunting prospect of dealing with a structure in the form of machine technology as opposed to the open methodology of relying on the human brain which presently is probably still pervasively used in translation classes.

Most of the translation instructors in this study, in any case, trust that possibly in the future when the quality of the MT yield is better, they can think seriously of introducing this innovation into their translation classes. These remarks appear to uncover an absence of comprehension of the convenience of MT as it stands today. What this paper disregards are the possibility of an MT framework ready to deliver close to-consummate yield, which is among the primary concerns. Should this become a reality, this would somewhat flag the finish line of conventional translation education and the beginning of an MT CATI period for when translation aptitudes are found to be inadequate without clear professional or career objectives. This supposition can be applied to or tested with other language pairs aside from Persian and English with lesser developed translation education curriculum.

\section{CONCLUSION}

The article set out above to study the perception among learners and educators of the viability of the application of MT and access-free internet-based translation services into translation teaching and learning. Four suppositions surrounding MT for instructive purposes were distinguished, namely (1) MT as a weak tool or wellspring of translation mistakes for adjustment, (2) MT as a useful tool or the application of translations database alongside other language tools, for example, corpora and concordances, (3) MT for professional use, for example for translation quality evaluation, prealtering and post-altering to improve translation professionals' work chances in the translation business, and (4) MT as "CATI" instrument to check students' command of L2 to sharpen students' translation abilities.

In a section after the first, this paper presented some ramifications of the MT application. Concentrating on access-free internet-based translation services as the highest open type of MT essentially appropriate for personal consumption and less for disseminating information purposes, a few suppositions were advanced with regards to the qualities and shortcomings of this innovation, together with some handy instances of utilizing MT for translation instruction purposes.

Finally, the last section of this article presented the observations, thoughts, and perceptions of translation students and translation instructors on the utilization of MT for translation teaching and learning. By and large, the utilization of MT and access-free internet-based translation services in translation education was seen as inventive learning and knowledge acquiring tool by both translation teachers and translation students. A great deal of attention was given to the benefits of using MT output or yield for comprehension or sensitizing purposes as much as the instructional benefit of acquainting interested translation students with MT and instructing them about its potential and impediments with the end goal of enabling them to approach MT critically yet with an open mind for more effective translation learning.

\section{LIMITATIONS AND FUTURE STUDIES}

So far the paper aimed to investigate the implementation of MT and particularly access-free internet-based services in translation courses through the viewpoints of learners and instructors. Nevertheless, future studies can investigate the use of MT in translation courses using other common software that is online/offline and also compares with the implementation of translation memories.

\section{ACKNOWLEDGMENT}

The authors are affiliated with Universiti Sains Malaysia. This paper was not funded by any organization. There is no competing interest.

\section{AUTHORS CONTRIBUTION}

The main and corresponding author has been the main contributor to the research idea, the early drafts of the paper, literature review, data collection, and analysis. The co-author is the supervisor and contributed through supervision, revising drafts, and partly with the discussion of findings.

\section{REFERENCES}

1. ALPAC [Automatic Language Processing Advisory Committee] (1966). Language and Machines: Computers in Translation and Linguistics. Washington, DC: National Academy of Sciences, Publication 1416.

2. AMTA (1994). Technology Partnerships for Crossing the Language Barrier: Proceedings of the first conference of the Association for Machine Translation in the Americas. October 5-8, Columbia, MD.

3. Anderson, D. D. (1995) Machine translation as a tool in second language learning. CALICO, 13(1): 68-97.

4. Baker, Mona, and Saldanha, Gabriela (eds) (2012). Routledge Encyclopedia of Translation Studies. New York: Routledge.

5. Balkin, Lorna, et al. (1991). "Declarative evaluation of an MT system: practical experiences." Applied Computer Translation 1, 3 (July-September), 49-59.

6. Ball, R.V. (1989) Computer-assisted translation and the modern language curriculum. CSS File 8: 52 -55. 
7. Belam, J. (2002) Instruction machine translation evaluation by assessed project work. In: 6th EAMT Workshop Instruction Machine Translation, Manchester, 131-136.

8. Belam, J. (2003) Buying up to falling: a deductive approach to instruction post-editing. In: Proceedings of the Workshop on Instruction Translation Technologies and Tools. MT Summit IX. New Orleans, United States, 110.

9. Campbell, S. 2002. Translation in the context of EFL - The Fifth Macroskill? TEFLIN, 13: 1

10. Chan, Sin-wai (ed.) (2015). Routledge Encyclopedia of Translation Technology. London/New York: Routledge. https://doi.org/10.4324/9781315749129

11. Cohen, A. and Brooks-Carson, A. 2001. Research on direct versus translated writing: Students' strategies and their results. The Modern Language Journal, 85: 169-188. https://doi.org/10.1111/0026-7902.00103

12. Corness, P. (1985) The ALPS computer-assisted translation system in an academic environment. In: Picken, C. (ed.), Translating and the Computer 7. London: Aslib, 118-127.

13. Davis, F.D, Bagozzi, R.P. and Warshaw, P.R. (1989) User acceptance of computer technology: a comparison of two theoretical models. Management Science, 35(8): 982-1003. https://doi.org/10.1287/mnsc.35.8.982

14. DeCesaris, J. A. (1995) Computerized Translation Managers as Instruction Aids. In: Dollerup, C. and Appel, V. (eds.), Instruction Translation and Translating 3: New Horizons, Amsterdam: John Benjamins, 263-269. https://doi.org/10.1075/btl.16.36dec

15. Dugast, Loïc, Senellart, Jean, and Philipp Koehn (2007). "Statistical post-editing on SYSTRAN's rule-based translation system." Proceedings of the Second Workshop on Statistical Machine Translation, Prague, June 2007. Association for Computational Linguistics, 220-223. ttps://doi.org/10.3115/1626355.1626387

16. Fiederer, R. and O'Brien, S. 2009. Quality and machine translation: A realistic objective? The Journal of Specialized Translation, 11: 52-72.

17. Flanagan, Mary A. (1994). "Error Classification for MT Evaluation.” AMTA (1994, 65-72).

18. French, R. J. (1991) Machine translation. In: Brierley, W. and Kemble I.R. (eds.), Computers as a Tool in Translation learning. Chichester: Ellis Horwood Limited, 55-69.

19. Garcia, I. 2010. Is machine translation ready yet? Target, 22(1): 7-21. https://doi.org/10.1075/target.22.1.02gar

20. Gaspari, F. (2007). The Role of Online MT in Webpage Translation. Ph.D. Thesis. The University of Manchester.

21. Goodman, Kenneth, and Sergei Nirenburg (1991) Eds. The KBMT Project: A Case Study in Knowledge -based Machine Translation. San Mateo, CA: Morgan Kaufmann Publishers.

22. Guerberof, A. 2009. Productivity and quality in the post-editing of outputs from translation memories and machine translation. Localization Focus, 7(1): 11-21.

23. Hutchins, W.J. (1986). Machine Translation: Past, Present, Future. New York: John Wiley \&Sons.

24. Isahara, H. et al. (1994). "Technical Evaluation of MT Systems from the Developer's Point of View: Exploiting Test-sets for Quality Evaluation.” AMTA (1994, 126-133).

25. Kaye, P. 2009. Translation activities in the language classroom. Teaching English, Retrieved from http://www.teachingenglish.org.uk/print/4726

26. Kliffer, M. D. (2005) An experiment in MT post-editing by a class of intermediate/advanced French majors. In: Proceedings EAMT 10th Annual Conference, 30th-31st May, Budapest, 160-165.

27. Kliffer, M. D. An experiment in MT post-editing by a class of intermediate/advanced French majors. In Proceedings of EAMT, 10th Annual Conference. Budapest, Hungary.

28. Kobayashi, H. and Rinnert, C. 1994. "Effects of first language on second language writing: Translation versus direct composition. In A.H. Cumming (Ed.)". In Bilingual performance in reading and writing, 223-255. Ann Arbor, MI: Research Club in Language Learning.

29. Koehn, Philipp (2017). "Neural Machine Translation." Statistical Machine Translation. Chapter 13. Johns Hopkins University. arXiv preprint arXiv:1709.07809

30. La Torre, M.D. (1999) A web-based resource to improve translation skills. ReCALL, 11 (3): 41-49.

31. Lewis, D. (1997) Machine translation in a modern languages curriculum. Computer-assisted Translation learning, 10: 255-271. https://doi.org/10.1080/0958822970100305

32. Liu, Qun, and Xiaojun Zhang (2015). "Machine Translation: General." Sin-wai Chan (ed.) (2015). Routledge Encyclopedia of Translation Technology. New York: Routledge, 105-119.

33. Moorkens, Joss, O'Brien, Sharon, da Silva, Igor A.L., de Lima Fonseca, Norma B., and Fabio Alves (2015). "Correlations of perceived post-editing effort with measurements of actual effort. Machine Translation 29(3-4), 267-284. https://doi.org/10.1007/s10590-015-9175-2

34. Neal, Jeanette G., et al. (1992). An Evaluation Methodology for Natural Language Processing Systems. Griffiss Air Force Base, New York: Rome Laboratory, Air Force Materiel Command. https://doi.org/10.21236/ADA263301

35. Niño, A. (2004) Recycling MT: A course on TRANSLATION writing via MT post-editing. Paper presented at CLUK (Computational Linguistics United Kingdom 7th Annual Research Colloquium), 6th and 7th January 2004 at the University of Birmingham, UK, 179-187. 
36. Niño, A. (2009) Machine translation in foreign translation learning: Language learners' and instructors' perceptions of its advantages and disadvantages. ReCALL 21 (2): pp.105-122. https://doi.org/10.1017/S0958344009000172

37. Niño, A. 2008. Evaluating the use of machine translation post-editing in the foreign language class. Computer Assisted Language Learning, 21(1): 29-49. https://doi.org/10.1080/09588220701865482

38. Nirenburg, Sergei, et al. (1992). Machine Translation: A Knowledge-based Approach. San Mateo, CA: Morgan Kaufmann Publishers.

39. NSF (1992). MT Evaluation: Basis for Future Directions. Proceedings of a workshop sponsored by the National Science Foundation. November 2-3, San Diego, CA.

40. Richmond, I.M. (1994) Doing it backward: Using translation software to teach target language grammaticality. In CALL 7 (1): 65-78. https://doi.org/10.1080/0958822940070106

41. Shei, C.-C. 2002. "Teaching MT through pre-editing: Three case studies". In 6th EAMT Workshop Teaching Machine Translation 89-98. Manchester.

42. Shei, C-C (2002a) Combining Translation into the Second Language and Second Translation learning: An Integrated Computational Approach. Ph.D. Thesis. The University of Edinburgh.

43. Shei. C-C (2002b) Instruction MT through pre-editing: Three case studies. In: 6th EAMT Workshop Instruction Machine Translation. Manchester, 89-98.

44. Slocum, Jonathan (1988), Ed. Machine Translation Systems. New York: Cambridge University Press.

45. Somers, H. 2003. "Machine translation in the classroom". In Computers and translation. A translator's guide, Edited by: Somers, H. 319-340. Amsterdam/Philadelphia: Benjamins. https://doi.org/10.1075/btl.35.20som

46. Systran. (2009). Report Document 2009. http://www.systransoft.be/download/annual-reports/systran-annualreport-2009.pdf (referred in 20.12.2018).

47. Thriveni, C. (2002). Cultural elements in translation: The Indian perspective. Translation Journal. 6/1 Retrieved on Nov. 2nd, 2009 from http://accurapid.com/journal/19culture.htm

48. Vauquois, B. (1968). A survey of formal grammars and algorithms for recognition and transformation in machine translation, IFIP Congress-68 (Edinburgh), pp. 254-260.

\section{APPENDIX A}

\section{TRANSLATION LEARNERS' MT EVALUATION QUESTIONNAIRE}

This questionnaire is designed to help to evaluate the effectiveness of the MT post-editing course. Please indicate your personal views upon the questions raised.

Please answer the questions by putting a tick $[\sqrt{ }]$ in the appropriate box

\section{SECTION A: COURSE}

Generally speaking, how did you find the course?

1. Overall impression:

What is your overall impression of the course?

Very bad [1] [2] [3] [4] [5] very good

2. Interest:

How interesting did you find it?

Very boring [1] [2] [3] [4] [5] very interesting

3. Usefulness:

How useful did you find it?

Not useful at all [1] [2] [3] [4] [5] very useful

Why? Please justify.

\section{Difficulty:}

How difficult did you find it?

Too easy [1] [2] [3] [4] [5] too difficult

Why? Please justify. 
5. Fun:

Did you enjoy it?

Not at all [1] [2] [3] [4] [5] very much

6. Length:

Did you find the course length appropriate?

Very short [1] [2] [3] [4] [5] very long

7. Learning:

Did you learn anything new?

I hardly learned anything [1] [2] [3] [4] [5] I have learned a lot

What have you learned?

\section{Materials:}

Did you find the materials appropriate?

The course materials were not good at all [1] [2] [3] [4] [5] The course materials were very good

\section{Assessment:}

Did you find the assessment appropriate?

Assessment was not good at all [1] [2] [3] [4] [5] The course assessment was

very good

10. How could the course be improved?

\section{SECTION B: MACHINE TRANSLATION}

1. Which process have you followed in your post-editing, i.e. have you looked at the MT output before or after doing your post-editing?

2. Have you used any other translation tool for your MT post-editing? If so, which one?

3. Are you going to use MT in the future? 
For which purpose?

4. Do you think MT is a useful translation tool?

Why?

5. Has MT helped you to improve your level of translation ability?

In which sense?

6. Has MT given you more confidence in your translation production?

In which sense?

Many thanks.

\section{APPENDIX B:}

\section{SURVEY FOR TRANSLATION INSTRUCTORS ON THE USE OF MT FOR TRANSLATION INSTRUCTION AND LEARNING PURPOSES}

1. Is MT familiar to you? $\square$ Yes $\square$ No

2. Where have you heard/read about MT? $\square$ Informal conversation $\square$ Internet $\square$ Articles

$\square$ Conference $\square$ Other

If you want to have a go with MT, the most accessible type is access-free internet-based translation services. Some sites you can browse are translate.google.com, bingtranslator.com.

You will need to do so before continuing with the rest of the survey. I would recommend you to input some general and specialized texts that you would use in your translation class.

3. If you have used MT, which programs have you used? $\square$ A commercial program such as SYSTRAN or Globalink $\square$ An online MT system

4. How frequently have you used it? $\square$ Everyday $\square$ Several times a week $\square$ Once a month $\square$ Several times a year $\square$ Never

5. For what purpose have you used it? $\square$ To read texts in other languages $\square$ To get communicated with speakers of other languages via chat or email $\square$ As a draft to write in 
other language $\square$ For curiosity $\square$ Other (please specify)

6. Have you used translation as an instruction/learning tool? $\square$ Yes $\square$ No

7. With which language pair? into

8. With which language level? $\square$ Beginners $\square$ Intermediate $\square$ Advanced $\square$ Higher $\square$ Improvers $\square$ All of them

9. In which language direction? $\square$ From L1 to L2 $\square$ From L2 to L1

10. With which text types? $\square$ General $\square$ Specialized (please specify)

11. For what purpose? $\square$ Reading comprehension in L1 $\square$ Reading comprehension in L2 $\square$ Written production practice $\square$ Revision $\square$ Assessment $\square$ Others (please specify)

12. Have you used MT in your lessons? $\square$ Yes $\square$ No

13. If you have used it, for what purpose? $\square$ Reading comprehension $\square$ Written production practice $\square$ Revision $\square$ Assessment $\square$ Others (please specify)

14. With which language pair? into

15. In which language direction? $\square$ From $\mathrm{L} 1$ to $\mathrm{L} 2 \square$ From $\mathrm{L} 2$ to $\mathrm{L} 1$

16. With which language level? $\square$ Beginners $\square$ Intermediate $\square$ Advanced $\square$ Higher $\square$ Improvers $\square$ All of them

17. With which text types? $\square$ General $\square$ Specialized (please specify)

18. Do you find it easy to use? $\square$ Yes $\square$ No

19. Do you find it useful? $\square$ Yes $\square$ No

20. Would you include hands-on practice on MT in a translation syllabus? $\square$ Yes $\square$ No

Suggestions:

21. If you have not used MT in your lessons, would you use it? $\square$ Yes $\square$ No

22. With which language level? $\square$ Beginners $\square$ Intermediate $\square$ Advanced $\square$ Higher $\square$ Improvers $\square$ All of them

23. In which language direction? $\square$ From L1 to L2 $\square$ From L2 to L1

24. With which kind of program? $\square$ A commercial program such as SYSTRAN or Globalink $\square$ An online MT system

25. With which text types? $\square$ General $\square$ Specialized (please specify) 
27. Which advantages do you think it has? $\square$ It is fast $\square$ It is user friendly $\square$ It easily creates ready-made texts for practice $\square$ It involves professional instruction $\square$ It involves written production practice $\square$ It involves error detection and correction practice $\square$ The teacher can control the input text $\square$ Others (please specify)

28. Which limitations do you think it has? $\square$ Low quality $\square$ Text type constraint (not suitable for creative texts) $\square$ Bad model $\square$ It requires instruction $\square$ Others (please specify)

Age: $\square$ Less than 30 years $\square$ Between 30 and 40 years $\square$ Between 40 and 50 years

$\square$ Between 50 and 60 years

Sex: $\square$ Masculine $\square$ Feminine

Nationality: L1:

Level of translation students that you teach/have taught: $\square$ Freshmen $\square$ Sophomore $\square$ Junior $\square$ Senior $\square$ Improvers $\square$ All of them

Comments:

Many thanks for your collaboration! 